\title{
STEROIDAL METABOLITES IN CHILEAN RIVER SEDIMENTS INFLUENCED BY PULP MILL EFFLUENTS
}

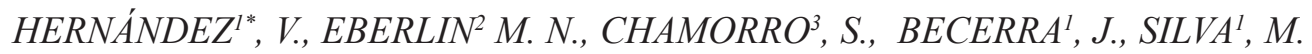 \\ 1) Natural Products Chemistry Laboratory, Faculty of Natural and Oceanographic Sciences, Concepcion, Chile. PO. Box 160-C. \\ ${ }^{2}$ Laboratorio Thomson of Mass Spectrometry, Science Faculty, University of Campinas, Campinas/SP, Brazil \\ 3) Centro EULA, Universidad de Concepción, Chile. \\ (Received: July 19, 2013 - Accepted: September 12, 2013)
}

\begin{abstract}
The Biobío River basin (central south of Chile) is highly impacted by a variety of anthropogenic activities such as pulp mills subjected to different treatment processes. The cellulose production has notoriously increased in the Biobío Region in the last years reaching more that $80 \%$ of country production. This industrial activity concentrates its production using as raw material fast growing vegetal species like radiata pine (Pinus radiata) and eucaliptus (Eucalyptus globulus). Environmental effects of this massive cellulose production is widely known in countries with major production, but is less addressed in Chile.

In this study we report the presence and concentrations of steroidal metabolites, such as sitosterol, campesterol and androstenedione in sediments at the Biobío River basin, considering the Laja, Biobío and Vergara rivers, in points where effluents of cellulose are dumped. Also was detected the presence of coprostanol, which is of human origin.
\end{abstract}

Keywords: Pulp mill effluents, steroidal metabolites, Biobio basin, Chile.

\section{INTRODUCTION}

Chile is currently one of the greatest worldwide cellulose producers and the environmental cost of this activity is yet uncertain. ${ }^{1}$ The generation of effluents from the production of cellulose, affects mainly to the Central Southern zone, in the Biobío basin region and have identified as a potential source of endocrinal activity in the receiving water bodies ${ }^{2-4}$ due to the presence, among others, of wood extractives such as fatty acids, sterols, phenolic compounds and terpenes (di and triterpenes are emphasized). ${ }^{5,6}$ Investigations carried out intended to recognize its real dimension are scarce but in constant development. ${ }^{2,7}$ This kind of compounds can cause physiological abnormalities ${ }^{1,5,8}$ or even morphological. ${ }^{3}$ Orrego et al. ${ }^{7,9}$ stated an increased size and precocious gonad maturity in females as well as an increase in the plasmatic vitelogenine in juvenile males of Oncorhynchus mykiss exposed to sediments influenced by effluents derived from the cellulose production in the Biobío River. Similarly, the intraperitoneal injection of extracts obtained by means of SPE to treated effluents reaffirmed what it was previously reported. ${ }^{3}$ Several authors have reported on the endocrine activity these effluents might have..$^{10,11,12}$ Chamorro et al. ${ }^{13}$ informed about the high estrogenicity related to effluents of the same industrial activity on the Biobío basin, even with tertiary treatment in the plant. If it is considered that these and other metabolites derived from a biological or chemical transformation in the same sediments can remain active even in very low concentrations, ${ }^{12,}{ }^{14}$ constituting a challenge to the analytics modern analysis techniques such as those derived from the advancement in mass spectrometry, which are able to reach increasing sensitivity in metabolite detection at trace concentrations. ${ }^{6}$

The aim of this study is to report the presence and concentrations of steroidal metabolites in sediments at the Biobío River basin (Laja, Biobío, and Vergara rivers), in points where effluents of cellulose mills have been released from three kraft process mills with secondary treatments.

\section{MATERIALS AND METHODS}

Samples of sediments used in this study were collected between September 2010 and April 2011 (Table 3), by means of a $1 \mathrm{~kg}$ capacity petit ponar dredge. Each sample was composed of 2 sub-samples in each site which was chosen based on the industrial activity of their surroundings. Thus, a site in the Laja city (L3) was chosen, $50 \mathrm{~m}$ downriver (in the Biobio river) from an effluent releasing point with secondary treatment of a kraft mill. Also, there are two reference point, located at $5 \mathrm{~km}$ and $10 \mathrm{~km}$ upstream from L3 (on the Laja River), so they were denominated as L2 and L1 respectively. On the other hand, two sampling points were chosen following the same reference of effluent releasing from cellulose producing companies. The first point was located in the Biobío River, near Negrete city and at $50 \mathrm{~m}$ from a kraft type treated effluent diffuser. This site received the name of BB1. The other sampling point was located $150 \mathrm{~m}$ downstream from the diffuser of another cellulosic plant with kraft process and secondary treatment of effluents, located at the Vergara River (V3) and two reference points located 500 (V2) and 1000 (V1) m upstream. In all cases, sediment samples were taken under controlled conditions for their later analysis. All samples were drained and packed in aluminium foils to be then transported in thermo insulated boxes to the laboratory and stored at $-4^{\circ} \mathrm{C}$ until their processing. ${ }^{15}$

Samples drained and fresh were used to estimate the content of organic matter by means of loss ignition in a muffle at $450{ }^{\circ} \mathrm{C}$ for three $\mathrm{h}$.

Extractions were carried out in homogenized $200 \mathrm{~mm}$ particle size samples by means of a Soxhlet for $16 \mathrm{~h}$, using dichloromethane pro analysi (p.a.) Merck. Samples were prepared by weighting $30 \mathrm{~g}$ of material with 8 g powder copper, in order to avoid chromatographic disturbances associated to the presence of sulphides or sulphuric material in the simples. Thereafter, extracts were concentrated until 1-2 mL by means of a rotatory evaporator under reduced pressure and resuspended in dichloromethane p.a. for the chromatographic runs.

In order to characterize the extracts, a chromatographic analysis was performed by the injection of $1 \mathrm{~mL}$ of sample in a gas chromatograph Agilent model 7890 A coupled to a mass detector Agilent model 5975 C. The chromatograph was equipped with a HP5-MS (J\&W Scientific capillary column of $30 \mathrm{~m}$ long and internal diameter of $0.25 \mathrm{~mm}$ and a melted silica film with a thickness of $0.25 \mathrm{~mm}$. Carrier gas was electronic grade helium in $3 \mathrm{~mL} /$ min flow, rising at $8{ }^{\circ} \mathrm{C} / \mathrm{min}$ until $180^{\circ} \mathrm{C}$ for $3 \mathrm{~min}$, rising then at $8{ }^{\circ} \mathrm{C} / \mathrm{min}$ until $250^{\circ} \mathrm{C}$ and keeping it for $15 \mathrm{~min}$.

Injector temperature was established in $250{ }^{\circ} \mathrm{C}$ and the detector, in $300{ }^{\circ} \mathrm{C}$ in scan mode, with scanning range between 50 and $500 \mathrm{amu}$. Ionization mode by electronic impact was set up in $70 \mathrm{eV}$. The database used to compare was the NIST.05 as part of Chemstation software.

The same temperatures for both oven and injector were programmed for Agilent 7890 gas chromatograph with flame ionization detector (FID) set up in $300{ }^{\circ} \mathrm{C}$. In this case, a J\&W Scientific HP-5 capillary column was used, with similar characteristics to those already described, to run 3 times each sample in order to quantify the extracts.

Calibration curves were prepared using sitosterol, campesterol, coprostanol, and androstendione with dichloromethane p.a. (Merck). With these curves, the obtaining of quantification limits as well as analite detection was also carried out, according to the studied samples.

$\mathrm{QA} / \mathrm{QC}$ values for quantitative characterization of sediments samples are shown in Table 1.

\section{RESULTS AND DISCUSSION}

Organic matter (Table 2) analyzed in sediment samples is relatively low, as a consequence of a medium sandy type fraction of grain of the sediments, which does not constitute a good organic matter deposit. Impact points represent a major percentage of organic matter due to the presence, evident in some cases, of particulate material from adjacent industrial effluents. That is the case of the sample L3, which presented an unpleasant sulphurous smell, as well as the abundant presence of fibres derived from the effluent both in sediment and in water. 
Table 1: Linear regression parameters for detection and quantification limits $\left(\mu \mathrm{g} g-{ }^{1}\right)$

\begin{tabular}{|c|c|c|c|c|}
\hline & $\boldsymbol{\beta}$-sitosterol & Campesterol & Coprostanol & AD \\
\hline $\mathrm{r}$ & 0.991 & 0.983 & 0.998 & 0.997 \\
\hline $\mathrm{LD}$ & 1.179 & 0.891 & 0.650 & 0.841 \\
\hline $\mathrm{LQ}$ & 2.03 & 1.50 & 0.973 & 1.260 \\
\hline
\end{tabular}

Linear regression statistics method was used for concentrations confirmation. LD: limit of detection; LQ: limit of quantification.

Table 2: Determination of the organic matter content (LOI \%).

\begin{tabular}{|c|c|}
\hline Sampling site (river point) & $\begin{array}{c}\text { Org. Mat. } \\
\text { (\%) }\end{array}$ \\
\hline Bio-Bio in Laja city (L3) & 1.33 \\
\hline Laja (L2) & 1.21 \\
\hline Laja (L1) & 1.25 \\
\hline Bio-Bio (BB1) & 0.96 \\
\hline Vergara (V3) & 1.24 \\
\hline Vergara (V2) & 1.17 \\
\hline Vergara (V1) & 1.10 \\
\hline
\end{tabular}

* Average value measured on the basis of two runs by each sample

The aim of this study was to measure a combination of environmental contaminants in the waterbed sediments: b-sitosterol, campesterol and androstenedione, among others. However, the presence of coprostanol is evidenced in concentrations ranging 0.3 and $6.2 \mathrm{mg} \mathrm{g}^{-1}$, which besides increasing the origin of contamination by informing the detection of compounds of both natural and introduced origin, provides a real approximation to the complex that a sediment sample from the rivers of the basin under study can turn out to be. This metabolite is present because of the discharges of domestic black waters, since there are no other facilities for these kinds of effluents.

Sitosterol medium concentration in these sediments reaches $2.2 \mu \mathrm{g} / \mathrm{g}^{-1}$ and the highest concentration was found in sample from the Vergara River (Table 3), downwater from the effluent diffuser. This natural origin steroidal metabolite is frequently found in riverbed sediments. However, its concentration increases in sediments under cellulose debris effluents. ${ }^{16}$

Data obtained in the removal of this metabolite in treatment systems operated under a regime of six days of retention time indicate that up to $96 \%$ can be eliminated in the effluent. ${ }^{13}$ However, concentrations lower than those informed here have been showed to generate a biological impact. ${ }^{2}$

Despite being selected the site BB1 (near Negrete city) to be downstream effluent diffuser, sitosterol was not detected, probably due to the scarcity of fine sediment in a river section of greater water current and consistent with the fewest organic matter analyzed.

Table 3: Metabolites quantified in studied sediments.

\begin{tabular}{|c|c|c|c|}
\hline Site & $\begin{array}{c}\text { Coprostanol } \\
(\boldsymbol{\mu g} \text { g- } \mathbf{~})\end{array}$ & $\begin{array}{c}\text { Campesterol } \\
(\boldsymbol{\mu g} \text { g- } \mathbf{)}\end{array}$ & $\begin{array}{c}\text { Sitosterol } \\
(\boldsymbol{\mu g} \text { g- } \mathbf{)}\end{array}$ \\
\hline L1 & $0.301 \pm 0.013$ & $0.554 \pm 0.027$ & $0.734 \pm 0.098$ \\
\hline L2 & $0.856 \pm 0.059$ & $0.815 \pm 0.041$ & $1.06 \pm 0.098$ \\
\hline L3 & $3.44 \pm 0.290$ & $1.60 \pm 0.190$ & $3.12 \pm 0.250$ \\
\hline V1 & $2.60 \pm 0.186$ & $1.44 \pm 0.034$ & $1.26 \pm 0.028$ \\
\hline V2 & $4.30 \pm 0.280$ & $3.10 \pm 0.046$ & $3.37 \pm 0.119$ \\
\hline V3 & $6.23 \pm 0.170$ & $4.79 \pm 0.160$ & $3.83 \pm 0,052$ \\
\hline BB1 & $<$ L.Q & $<$ L.Q & $<$ L.D \\
\hline
\end{tabular}

Values $\left(\mathrm{mg} \mathrm{g}^{-1}\right)$ were obtained by averaging of three replicates for each sample. Standard deviation is indicated.

Sites and concentrations detected for sterols were compared using two ways ANOVA. There are significant differences between the sites and the concentration for the compounds detected $(\mathrm{F}=32.412, \mathrm{p}=0.000)$. In addition, it was determined that there are significant differences in the concentrations of the different sites $(\mathrm{F}=978.755, \mathrm{p}<0.005)$.

All calculations were performed with the software package STATISTICA (7.0).

A fine characterization of sediments extracts was done by means of the ESI-FT ICR-MS ionization by electrospray technique, coupled to mass spectrometry of ion cyclotronic by Fourier transformation (FT-ICR-MS) in the ThomSon - Mass Spectrometry Laboratory at the University of Campinas.

Although the presence of androstenedione was not detected by GC-FID in concentrations higher than the detection limit, its presence as well as for trihidroxy-androstenedione, pregnenolone, 17-hidroxy-androstanone and hidroxypregnanedione was evidenced in the site Laja 3 which is according with the expected due to lipophilicity of the compounds and because the area is associated with the oldest pulp mill plant in Chile. ${ }^{17}$

\section{CONCLUSIONS}

The presence of these metabolites adsorbed to the waterbed sediments constitutes a clear signal that the rivers of the Biobío basin are being contaminated by effect of the discharge of effluents from the secondary treatment systems of cellulose companies. There are reasonable suspicions on these metabolites of acting as environmental endocrine disruptors. Currently, Chile does not have a norm for the regulation of these chemicals in the effluents that are spilled into water bodies which besides; it is a contradiction to the precautionary principle that should be used in these cases, even more if it is considered that from these rivers, drinking water for a population of nearly 3 million inhabitant is obtained.

Also, because of the obtained results, it is possible to affirm that there is not only contamination by industrial waste, but also due to house dumping sewage, activities of lesser magnitude but they must be monitored in order to prevent possible problems in the future.

These metabolites in waterbed sediments indicates that the rivers are being contaminated by environmental estrogens mainly originated by the pulp mill activity in the area and, to a lesser extent, by discharges from domiciliary sewage. It is possible that in environments formed around these discharges biotransformation processes are developed from certain metabolites into others with greater or lesser activity. This constitutes a major issue because their adverse effect has been demonstrated for both aquatic vertebrates and invertebrates from this basin, even more considering the fact that this could be a synergic type action in metabolites such as those detected in concentrations lower than our detection limit. Understanding how human activities can impact on the life of native fishes from the Biobío River is a key antecedent for designing plans for its conservation.

\section{ACKNOWLEDGEMENTS}

Financial support by FONDECYT Postdoctoral Project 3100122 is gratefully acknowledged by the authors.

\section{REFERENCES}

1. G. Chiang, K. Munkittrick, R. Orrego, R. Barra. Water Qual. Res. J. Canada. 45, 111, (2011).

2. S. Chamorro, V. Hernández, E. Monsalvez, J. Becerra, M. Mondaca, B. Piña and G.Vidal, Bull. Environ. Contam. Toxicol. 84, 165, (2010)

3. R. Orrego, J. Guchardi, V. Hernandez, R. Krause, L. Roti, J. Armour, M. Ganeshakumar, D. Holdway. Environ. Toxicol. Chem. 28, 181, (2009)

4. M. Hewitt, J. Parrott, M. McMaster. J. Toxicol. Environ. Health - Part B: Critical Reviews, 9, 341, (2006)

5. V. Hernández, J. Gavilan, J. Becerra and M. Silva. J. Chil. Chem. Soc, 53, $1718,(2008)$

6. M. Ikonomou, S. Cai, M. Fernandez, J. Blair, M. Fischer. Environ. Toxicol. Chem., 27, 243, (2008)

7. R. Orrego, A. Burgos, G. Moraga-Cid, B. Inzunza, M. González, A. Valenzuela, R. Barra, and J. Gavilán. Environ. Toxicol. Chem. 25, 2280, (2006)

8. J. Brian, C. Harris, M. Scholze, A. Kortenkamp, P. Booy, M. Lamoree, G. Pojana, N. Jonkers, A. Marcomini and J. Sumpter. Environ. Sci. Technol., 41, 337, (2007)

9. R. Orrego, G. Moraga-Cid, M. Gonzalez, R. Barra, A.Valenzuela, A. Burgos and J. Gavilán. Environ. Toxicol. Chem. 24, 92, (2005)

10. J. Carson, R. Jenkins, E. Wilson, W. Howell, R. Moore. Environ. Toxicol. 
Chem., 27, 1273, (2008)

11. M. Fernandez, M. Ikonomou and I. Buchanan. Sci. Total Environ., 373, 250, (2007)

12. R. Jenkins, E. Wilson, R. Angus, W. Howell, M. Kirk, R. Moore, M. Nance and A. Brown. Environ. Health Persp., 112, 1508, (2004)

13. S. Chamorro, C. Xavier, V. Hernández, J. Becerra and G. Vidal. Electron. J. Biotechnol., 12, 1 , (2009)
14. B. Karrasch, O. Parra, H. Cid, M. Mehrens, P. Pacheco, R. Urrutia, C. Valdovinos and C. Zaror. Sci. Tot Environ., 359, 194, (2006)

15. F. Tian, A. Wilkins and T. Healy. Bull. Environ. Contam. Toxicol., 60, 441, (1998)

16. P. Meriläinen, I. Lahdelma, L. Oikari, T. Hyötyläinen and A. Oikari. Chemosphere, 65, 840, (2006)

17. S. Chamorro, V. Hernández, V. Matamoros, C. Domínguez, J. Becerra, G. Vidal, B. Piña and J.M. Bayona. Chemosphere, 90, 611, (2013) 